\title{
Effectiveness Of Energy Sector Quality Management Systems In Response To Electrical Fire Disaster In Kisumu County, Kenya
}

\author{
Hassero, C., Dr. Nabiswa, F. \& Rev. Dr. Odhiambo, E .O. S. \\ Masinde Muliro University of Science and Technology, Kenya Department of Emergency Management Studies \\ DOI: 10.29322/IJSRP.10.11.2020.p10752 \\ http://dx.doi.org/10.29322/IJSRP.10.11.2020.p10752
}

\begin{abstract}
Globally, utility power transmission and distribution systems are described along with their observed vulnerabilities to natural and man-made hazards. At national level, approximately $40 \%$ of the load in the Western region is supplied via $33 / 0.433 \mathrm{kV}$ secondary distribution transformers. This contributes to transformer overload strain thus contributing to electrical fire disasters and outages. Kisumu substations are overloaded in the existing system under peak load conditions due to low thermal rating of conductors as a result of inadequate sizing. Several line sections feeding a large proportion of the load are of conductor type $25 \mathrm{~mm} 2$ ASCR causing an effective bottleneck leading to power outages and electric fire disasters. Due to these, the study sought to assess the effectiveness of energy sectors quality management systems in response to electrical fire disaster in Kisumu County. Cross-functional management model and Crosby Theory of Quality theories guided the study. A descriptive research design was used in the study. Sample size of the study was selected using purposive, census and stratified random sampling from the energy sectors; Kenya Power and Lighting Company, Kenya Electricity Transmission Company, Kenya Energy Generating Company and customers connected to electricity grid. The structured questionnaires, interviews guides and observation methods were used to collect data. Quantitative data was analyzed using descriptive statistics while qualitative data responses using thermalized and frequencies. Organizations have not ensured ISO certification requirements in their management systems. That organizations quality management systems were less effective in relation to electric disasters response. The paper recommends that all organization should implement ISOcertification requirements on their management systems. Effect their systems through assistance from other organizations with the same role for effective electric disaster management.
\end{abstract}

Index Terms- Disaster Management Systems, Electric Disaster and Quality Management Systems

\section{INTRODUCTION}

$\mathrm{G}$ lobally, utility power transmission and distribution systems are described along with their observed vulnerabilities to natural and man-made hazards. Considering the preparation for and effects of widespread electrical disasters, it is worthwhile reviewing recent major electricity outages. For instance, earthquakes, tsunamis, hurricanes and floods destroy transmission and distribution systems, including cables, towers and utility poles. Sioshansi (2011), argues that restoration of this infrastructure take very long periods of time.

Major pieces of infrastructure such as generators get flooded or roads blocked, limiting delivery of fuel supplies to local generators. Further, electrical equipment belonging to consumers can be swamped with water, posing the risk of electrocution, and therefore loss of lives (Krishnamurthy and Kwasinski, 2013). This means that power equipment must meet the required standards to ascertain qualities in considerations of type of hazard.The efficiency of the transmission and distribution network shows gap in both technical and non-technical terms. The technical aspect reveals lack re-conducting of lines, installation of capacitors, and construction of additional feeders and substations that withstand hazards and stabilize power distribution. On the other hand, nontechnical revealed lack of introducing electronic meters, improvement of meter reading accuracy, fraud control and resolution of billing anomalies (Tan, et al., 1998).

Kisumu County is served by the $132 \mathrm{kV}$ transmission system feeds 10 132/33 kV bulk supply points. The $33 \mathrm{kV}$ network comprises 52 radial feeders, 71 primary substations and approximately $2000 \quad 33 / 0.4 \mathrm{kV}$ distribution transformers. Approximately $40 \%$ of the load in the Kisumu County is supplied via $33 / 0.433 \mathrm{kV}$ secondary distribution transformers. There are small generating stations at Gogo Falls and Eburru, which generate electricity from hydro and steam resources respectively (Greenwire et al., 2008).

However, transformers at Kisumu, Kegati 132/3 $3 \mathrm{kV}$ substations are overloaded in the existing system under peak load conditions. Further, voltage and loading issues are evident on the Kondele feeder supplied from Obote Road primary substation. This is due to low thermal rating of conductors as a result of inadequate sizing. Several line sections feeding a large proportion of the load are of conductor type $25 \mathrm{~mm} 2$ ASCR causing an effective "bottleneck". Sinei (2013), argued that planning guidelines provided by KPLC have not been applied during the extension of a spur from the main feeder. Some of the electric gadgets are not standard which causes outages. Further, manual recording, he argues, result in erratic values that may not represent the true load behavior. 
The measurements at the substation transformers are seldom recorded. At peak hours, the load is high such that power is lost in some parts of this region. Sometimes, it takes long to restore power. The power supply doesn't meet demand, and therefore, power fluctuations are norms. According to Greenwire et al (2008), secondary transformers do not guarantee stable power supply, and therefore, power fluctuations would lead to electric disasters such as outages.

\subsection{Statement of the problem}

Power transmission and distribution systems are affected by vulnerabilities as a result of natural and human induced disasters. For instance, these disasters damages electrical facilities and thus affecting transmission and distribution systems (Krishnamurthy and Kwasinski, 2013).

Kenya Energy Sector organizations are making loses as a result of poor quality management systems, resulting to electric induced fires that lead to destruction of property and loss of lives (Vanya, 2015).

Kisumu County are known for heavy storms and strong winds. Power outages are common and electrical fire disasters related to the same are common. Approximately $40 \%$ of the load in the Kisumu region is supplied via $33 / 0.433 \mathrm{kV}$ secondary distribution transformers. Secondary transformers do not guarantee stable power supply, and therefore, power fluctuations lead to electrical disasters as a result of outages (Greenwire et al., 2008).

The preparation, mitigation, response and recovery from electrical disasters at Kenya energy sector are determined with level of management systems the companies possess, which it is not addressed to forestall electric disasters (Sinei, 2013). It's in view of this that the study evaluates the effectiveness of energy sector quality management systems in response to electrical fire disaster in Kisumu County.

\subsection{Objective of the study}

The objective of the study was to assess the effectiveness of energy sector quality management systems in response to electrical fire disaster in Kisumu County.

\subsection{Research Question}

How effective is the energy sector quality control system in relation to electrical fire disaster in Kisumu County?

\subsection{Justification of the Study}

From a research and academic perspective, previous studies have concentrated on issues of strategic management, Marnay et al., (2008) and change management in energy sectors (Sinie, 2013). Therefore, the study will assist both the state and private organization in various perspective.

\subsubsection{Academic Justification}

From academic perspective, the study by Njenga (2016) focused on quality management practices and performance of energy sector parastatals in Kenya, without giving attention to their influence to electrical fire disasters hence the gap. It is on this basis that the study went a notch higher to fill the identified gap thereby, investigating the influence of Kenya Energy Sector's

This publication is licensed under Creative Commons Attribution CC BY.

http://dx.doi.org/10.29322/IJSRP.10.11.2020.p10752
Quality Management Systems with regard to electrical fire disaster in Kisumu County.

The study will provides a foundation for further research in the field of disaster management. The findings of the study will improve the academics in electrical fire disaster response among organizations, and how energy organizations should adopt use of quality management systems in daily running in their functions and beyond by increasing reference materials in academic institutions to act as training manual for corporates.

\subsubsection{Policy Justification}

From a policy perspective, previous study by Sinei (2013), exploring management issues at energy sectors and how these management policies affect performance. This study have suggested policy change with regard to quality management systems such as design, planning and standards of electrical equipment that bring about electrical fire disasters as a result of natural or man-made hazards. Thus, policy makers in the energy sector would improve on quality of electric equipment, management of power lines and how to prepare, respond and recover from electric disasters.

\section{2.1 NATURE AND EXTENT OF QUALITY MANAGEMENT SYSTEMS WITH REGARD TO ELECTRICAL FIRE DISASTERS}

The connection between utility power transmission and distribution systems and vulnerabilities to natural hazards or human induced is obvious. Natural hazards include winter storms (freezing rain, snow and ice), high-wind events (hurricanes, tornadoes, and nor'easters), flooding (riverine and coastal), storms and earthquakes. Each of these hazards presents a unique set of design challenges for electrical transmission and distribution power systems (Sioshanis, 2011).

Sioshanis further argues that considering the preparation for and effects of widespread electrical fire disasters, it is worthwhile reviewing recent major electricity outages. This electric disaster led to untold damage from natural disasters in recent years in many a nation. For instance, earthquakes destroy transmission and distribution systems, including cables, towers and utility poles. The restoration of this infrastructure and the services it provides take very long periods of time. Further, electrical equipment belonging to consumers can be drowned with water, posing the risk of electrocution, and therefore loss of lives.

Major electric outages do not just occur due to natural events such as earthquakes or storms. Moreover, relatively minor incidents such as a small fire or a single downed transmission line trigger events that can cause cascading failures and result in widespread electrical failure, as happened in Italy in 2003 and India in 2012. More importantly, as well as reviewing the impact of the major electrical disasters is should be done to improve the reliability and resilience of electricity supply (Su, et al., 2008).

Blyden and Lee (2006), concurs that the centralized nature of many power systems means that relatively small damage, in a few key areas, can lead to extensive power outages. These vulnerable areas were not identified prior to the disaster.

Electricity networks contain significant amounts of distributed generation, yet such generation cannot be relied upon to maintain electricity supply after a major electric disaster. In general, this is 
an issue of planning and analysis within a power company. If this not the case, facilities and end-users face significant uncertainty in how to evaluate the risks of natural disasters, or their preparedness against such risks. Without any uniform way of measuring these risks, or preparedness for them, it is difficult for facilities to evaluate their own position, to prepare detailed disaster resilience or recovery plans, or compare one facility against another (Marnay et al., 2008).

According to Krishnamurthy and Kwasinski (2013), the key factors in minimizing the damage and costs associated with major electric outages is the quality of planning how well prepared an organization was to avoid loss of electricity supply after a major disaster, and, quite separately, how well the recovery from a major electric outage was planned.

From this review, planning needs to have continuity which is a key requirement for any successful business and coping with major outages whether from communication infrastructure failures or cyber-attacks is a critical task for organizations such as data centers. Thus, standardization of activities that provide guidelines and codes of practice for planning against major interruptions in many power companies is quit important. The following sub-section looks at how electric disasters relate directly to QMS of Kenya Power and Lighting Company.

Given the complexity of electricity systems and the growing popularity of distributed generation and related energy technologies in customer's premises, a new continuity plan specifically focused on electricity supply resilience and restoration is needed in many organizations. So-called ECP will specifically consider how to rapidly restore electricity supply to a particular site, based either on outside supply or internal provision (Marnay et al., 2008). Thus, preparedness against disaster will never be perfect without appropriate operational strategies. Installation of a back-up system or micro grids reinforce the preparedness against disaster.

In contrast to $\mathrm{BCP}$, unique electrical issues that should be considered by an ECP include: Alternative generation sources, the use of local back-up generation; dependencies outside the electrical equipment that may affect electricity supply for example, the availability of fuel for back-up generators and identification of particular electrical loads, their priority for business functions, and their energy requirements (Heavey et al., 2014).

Blyden and Lee (2006), noted that electrical fire disasters impact depends on the country, geography and infrastructure. Thus, the ECP metrics need to be carefully selected and assessed in terms of the insight they offer regarding the likely impact on electricity supply. The ultimate aim to standardize the way of measuring and comparing potential natural disasters is critical.

Krishnamurthy and Kwasinski (2013), argues that once an understanding of likely disasters and their severity has been established, a facility can then start to evaluate to what extent it is prepared against each disaster. The goal is to design a standard set of metrics that can indicate a facility's preparedness against disaster and loss of energy supply, effectively allowing the level of preparedness of each facility to be compared to one another.

There is currently no standard method to specify a load's electricity supply requirements. Such classifications may be based on individual pieces of equipment, where classes of load are introduced based on metrics such as: Acceptable supply interruption duration; acceptable supply frequency range and acceptable supply voltage range (Basir et al., 2011).

\subsection{The Electricity Continuity Systems and Disaster Response}

To stabilize power supply and minimize electrical disasters, backup systems are critical. By best practice, renewable energies (that is photovoltaic and batteries) are effective for maintaining energy during disasters (Sioshansi, 2011).In this specific case, it was only after the incident that consumers recognized the fact that distributed generations, such as photovoltaic generations and $\mathrm{CHP}$ systems that are installed to realize carbondioxide $(\mathrm{CO} 2)$ zero emission houses are successful in quickly recovering electricity supply in the case of disasters.

ECS detects loss of power from the grid by delinking function for grid and micro grid; power supply and monitoring functions from batteries to micro grid; checking function for safety inside micro grid; communication tool to check safety of connected appliances before recovery from blackout and minimizing power loss and saving conversion loss by DC power. Secondly, using renewable energies ensure penetration ratio (efficient utilization), capacity of batteries (Gravin et al., 2017).

\subsection{Kenya Energy Sector's Quality Management Systems in regard to electrical fire disasters in Kisumu County}

Electrical fire disasters in form of economic losses affect both KPLC and customers. KPLC, designs associated with construction or rehabilitation contributes to economic losses. For example, the sizing conductors and transformers in the energy sector not only minimize losses to an economic level, but also implements not the lowest construction cost solution, but the lowest lifetime cost solution. Generally, losses will be maintained at acceptable levels if planning guidelines are followed and network parameters are maintained within the planning limits. This means keeping: Voltage within required range; Equipment loaded to standard levels; and Power factor at optimal levels (Rossi et al., 1999).

Sinei (2013), argues that the most cost effective way to reduce losses at the distribution level is to ensure that maintenance and construction problems are corrected. She argues that poor jointing practice and materials add unnecessary losses to feeders, and can often lead to line failures and therefore electric disasters.

That developments to respond to outages and on-going maintenance, is generally not fixed on a permanent basis. Kenya Power and Lighting Company report indicate that the bus couplers on the $33 \mathrm{kV}$ and $11 \mathrm{kV}$ busbars are operated open at Sibembe and Obote Road primary substations.

With such planning, however, transformers at Kisumu and Kegati 132/33 kV substations are overloaded in the existing system under peak load conditions. Voltage and loading issues are 
evident on the Kondele feeder supplied from Obote Road primary substation. This is due to low thermal rating of conductors as a result of inadequate sizing. Several line sections feeding a large proportion of the load are of conductor type $25 \mathrm{~mm} 2$ ASCR causing an effective "bottleneck". Evaluation suggests that the planning guidelines provided by KPLC have not been applied during the extension of a spur from the main feeder (Otuki, 2017).

\subsection{Conceptual Framework}

\subsubsection{Cross-functional management model}

Juran cross-functional management approach comprises three legislative processes:

Quality Planning: a process that involves creating awareness of the necessity to improve, setting certain goals and planning ways to reach those goals. This process has its roots in the management's commitment to planned change that requires trained and qualified staff.

Quality Control: a process to develop the methods to test the products for their quality. Deviation from the standard will require change and improvement.

Quality Improvement: a process that involves the constant drive to perfection.

According to Juran (1992), Quality improvements need to be continuously introduced. Problems must be diagnosed to the root causes to develop solutions. The Management must analyze the processes and the systems and report back with recognition and praise when things are done right.

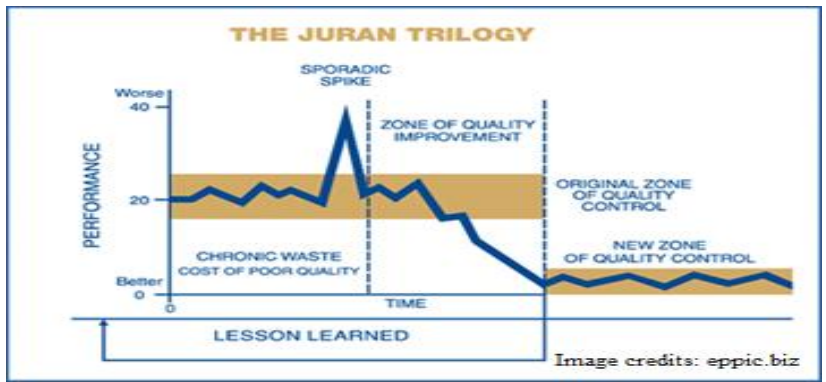

Figure 1. Cross-functional management model Source: The Juran Trilogy, 1992

Basing on his work, he viewed that organizations progress depends on implementation of strategies basing on; structured on a regular basis with commitment and a sense of urgency, building an extensive training program and cultivate commitment and leadership at the higher echelons of management if they are to achieve high quality.

Quality by design incorporates modern tools to preemptively control variation (Juran, 1992). These tools and methods begin by measuring and understanding the variation that exists by using historical data, testing, and modelling to help forecast, analyze, and eliminate the deleterious effects of variation using standard statistical techniques. Process control consists of three basic activities: Evaluate the actual performance of the process, compare actual performance with goals and take action on the difference. The final activity of the quality by design process is to implement the plan and validate that the transfer has occurred.

\subsubsection{Crosby Theory of Quality}

This publication is licensed under Creative Commons Attribution CC BY

http://dx.doi.org/10.29322/IJSRP.10.11.2020.p10752
Crosby's principle, Doing It Right the First Time, was his answer to the quality crisis. He defined quality as full and perfect conformance to the customers' requirements. The essence of his philosophy is expressed in the Absolutes of Quality Management and the Basic Elements of Improvement (Creech, 1994).

\subsubsection{Zero Defects}

Crosby's Zero Defects is a performance method and standard that states that people should commit themselves too closely monitoring details and avoid errors. By doing this, they move closer to the zero defects goal. According to Crosby, zero defects was not just a manufacturing principle but was an allpervading philosophy that ought to influence every decision that we make especially energy sectors. Managerial notions of defects being unacceptable and everyone doing 'things right the first time' are reinforced (Crosby, 2012).

\subsubsection{The Quality Vaccine}

Crosby explained that this vaccination was the medicine for organizations to prevent poor quality.

Integrity: Quality must be taken seriously throughout the entire organization, from the highest levels to the lowest. The company's future will be judged by the quality it delivers.

Systems: The right measures and systems are necessary for quality costs, performance, education, improvement, review, and customer satisfaction.

Communication: It is required to communicate the specifications, requirements and improvement opportunities of the organization. Listening to customers and operatives intently and incorporating feedback will give the organization an edge over the competition.

Operations: a culture of improvement should be the norm in any organization, and the process should be solid.

Policies: policies that are implemented should be consistent and clear throughout the organization. Figure 2 showing the interaction of the variables. 


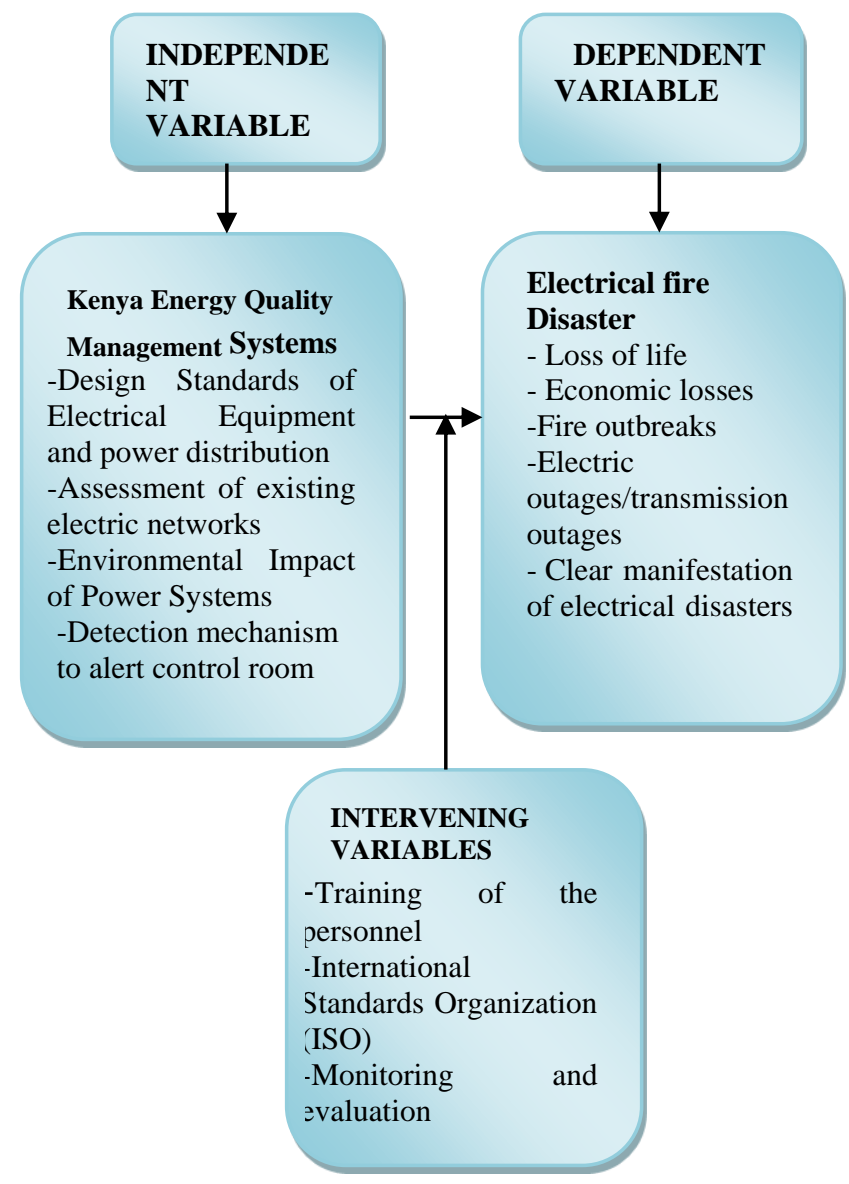

Figure 2: Conceptual framework model showing variables interactions

\section{Source: Researchers (2019)}

\section{RESEARCH METHODOLOGY}

\subsection{Research Design}

The study was qualitative in approach; with a single overall objective aimed to examine the effectiveness of energy sector quality management systems in response to electrical fire disaster in Kisumu County. Descriptive survey design was conducted in the selected areas of Kisumu County considered appropriate to enhance an apt determination of the state of quality management systems and their effectiveness in response to electric fire disasters.

\subsection{Sample Size Determination and Sampling Procedure}

A sample size of one hundred and sixty respondents drawn from energy sectors and customers connected to electricity grid clusters was used in the study. The sample size was drawn from the target population of 1865 by use of purposive sampling in which $(30 \%)$ technique applied in selection of respondents from the identified five organizations; KEBS, Energy Regulatory Commission, KENGEN, KPLC and KETRACO. Customers connected to the electricity grid also formed part of the sample size.
Both primary and secondary data collection was used to collect the relevant information. Primary data was collected from the field through structured questionnaires, interviews guides', observation checklist, focused group discussion and document analysis. The use of several data collection methods was enable the researcher to avoid the deficiency that springs from using one method of data collection method (Kothari, 2004). Secondary data was collected by analysis of publications such as electrical fire disaster journals, electricity/energy related legislations and government documents.

\subsection{Data Analysis}

The collected data was cleaned by listing, removed errors and checked extreme values and edited to ensure conformity. The group survey data was analyzed using SPSS Version 27. The variables were subjected to descriptive statistics. Quantitative data was analyzed using descriptive statistics such as frequencies and percentages. Findings were presented in form of frequency tables, pie charts, bar graphs and narratives.

\section{RESUlTS}

\subsection{Organization ISO certification requirements on management systems}

\subsection{Data Collection Methods}




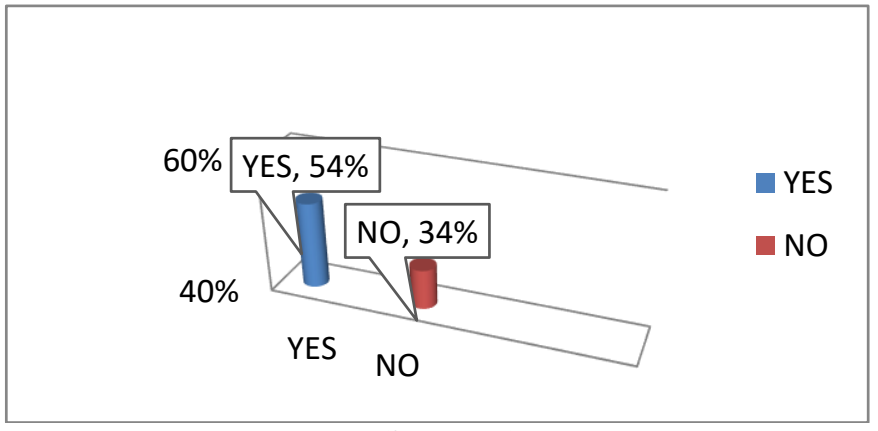

Figure 3: Organization ISO certification requirements in management systems

Source: Field Data Analysis (2019)

Data analysis showed that $85(54 \%)$ of the respondents under "YES" response agreed that their organizations ensured ISO certification requirements in their management systems while 56 (34\%) of the respondents were under "NO" response, implying that their organizations had not ensured ISO certification requirements in their management systems. The threshold between the respondents who were of the opinion under yes response and no response was $20 \%$, indicating that even if other organizations have it, they have not yet realized its vital role in quality management. The response rate is in exclusion of the customers connected to the electricity grid since they were not part of energy organizations.

Basing on the findings, the fact that the Anti-Counterfeit Agency had put contraband electrical cable importers on a notice warning of stringent penalties showed that the respondent's response on yes opinion was because of preserving reputation of their firm, thereby research finding contradicting relied information by Gravin et al (2017), that anti-Counterfeit Agency (ACA) claimed that illegal sub-standard electrical cables importation posed great harm to Kenyans. The case of containers impounded in a Mombasa Freight station containing over 2,000 electrical cables purportedly destined for the South Sudan market thus sparkling the need for inter-agency efforts to reinforce arrangements for pre-shipment inspection of products coming into the country.

Commercial wooden pole treatment plants; Kakuzi, Gilgil Telecommunications E A Cabro Industries, Timsales Ltd, Typsy Timber Treatment Ltd, Kuza, Comply Ltd and Muringa Holdings Ltd with an installed capacity of more than one million power transmission poles per year was also powering the fraud (Gravin et al., 2017). There was no assessment of suppliers who had a Quality Management System (QMS) that was based on ISO, which was the role of organization basing on factors of production for customer satisfaction. Supply of sub- standard poles or other equipment to the energy organizations causes frequent outbreaks of fire and damaged electrical gadgets in Kisumu County (Tricker, 2005).

The research conducted in Ghana by Ghana Electrical Association (GEA), indicated that the energy sectors was in for making profit but not considering the safety of the customers because no measures were taken to those individuals who bargained for old electrical cables retrieved from old or dilapidated buildings for re-use in their buildings with some also purchased the less expensive ones, claiming the local one were too expensive to afford. This indicated that there was no standard material designed and accepted by energy organizations to use and direct its customers to purchase yet other materials caused hazard. That use of non-copper conductors lead to cable over-heating, fire outbreaks, and electric shocks from walls; and damaged appliances (Cavallini et al., 2007).

According to Cavallini et al (2007), Kenya Power and Lighting Company (KPLC), Kisumu office experienced a fire outbreak at the Information and Communication Technology server room. The chief security officer confirmed that the cause of fire was an electric fault as the room was locked and no one was around when the fire started. This show the need for organization ISO certification requirements on management systems.

\subsection{Effectiveness of organizations systems in relation to electric disasters quality management service provision}

ISO 9001:2015 is the most recognized and implemented quality management system standard in the world. ISO 9001:2015 specifies the requirements for a QMS that organizations can use to develop their own programs (Dennis, 2007). Each element of a quality management system helps achieve the overall goals of meeting the customers' and organization's requirements including the organization's quality policy and quality objectives. Figure 5.4 shows the response on effectiveness of organizations systems in relation to electric disasters quality management service provision.

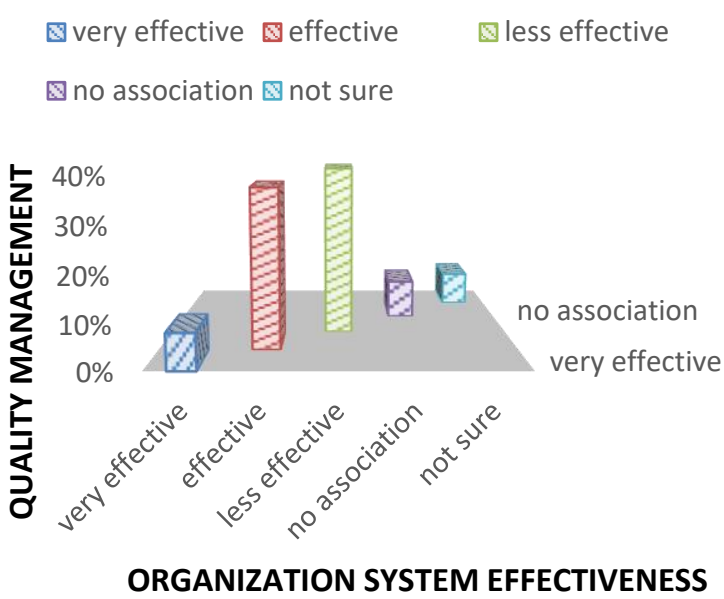

Figure 4: Effectiveness of organizations systems in relation to electrical fire disasters quality management service provision Source: Field data (2019)

Out of 160 respondents, 19 (12\%) of the respondents from customers connected to the electricity grid were excluded because of the nature of the data that the respondents were asked to give. Therefore, the response rate was $141(88 \%)$. 11 (7\%) of the respondents had views that their organization had very effective systems in relation to electric disasters quality management service provision. Supported by $53(33 \%)$ of the respondents under effective opinion. 61 (38\%) of the respondents claimed that their organizations systems in relation to electric disasters quality management service provision were less effective. $10(6 \%)$ were of the opinion that it had no association while $6(4 \%)$ of the respondents were not sure if their organizations systems in relation 
to electric disasters quality management service provision were effective or not.

From the analysis, it is clear that the organizations systems in relation to electric disasters quality management service provision were less effective. The research findings corroborates, focus group discussion in which $45(28 \%)$ of the respondents argued that their organization had less effective systems efficiency in relation to electric disasters quality management service provision. That if their systems were effective, they would not be experiencing issues of electric disasters hence satisfaction to their customers. One of the respondents had observation that;

"The fact that our customers have resort into use of alternative source of energy leaves us with lingering questions in relation to our service delivery and this is majorly contributed by weak systems." (Interview with a KPLC employee, 20 $0^{\text {th }}$ August, 2019 in Kisumu Kibos sub-station).

According to Juran and Joseph (1995), quality management can be ensured through focusing on Quality control (QC). A part of quality management focused on fulfilling quality requirements, is a process by which entities review the quality of all factors involved in production. Quality control emphasizes on three aspects. Elements such as controls, job management, defined and well managed processes, competence, such as knowledge, skills, experience, and qualifications.

According to Dennis (2007), inspection is a major component of quality control, where physical product is examined visually and the end results of a service are analyzed. The quality of the outputs was at risk if any of these three aspects is deficient in any way. For instance, Energy organizations risk the life of its customers because monitoring and predicting devices mounted on their equipment to relay information in case of a hazard prediction. Lack of Communicating risk information and reliable warnings to potentially affected locations through their communication systems made it difficult to counter issues of defect response and this further puts the customers in danger (Anton et al., 2016).

On ISO certification, there is defined part of quality control which focuses on providing confidence that quality requirements has to fulfil. This defect prevention in quality assurance differs subtly from defect detection and rejection in quality control. That Quality assurance (QA) was a way of preventing mistakes and defects in manufactured products and avoiding problems when delivering products or services to customers (Hoyle and David, 2005).

Quality assurance comprises administrative and procedural activities implemented in a quality system so that requirements and goals for a product, service or activity were fulfilled. Defining what suitable product or service quality has been a difficult process, determined in many ways, from the subjective user-based approach that contains the different weights that individuals normally attach to quality characteristics, to the value-based approach which finds consumers linking quality to price and making overall conclusions of quality based on such a relationship (Sadikoglu and Olcay, 2014).

4.3 Influence of state and type of equipment on preparedness and response to electrical fire disasters in Kisumu County

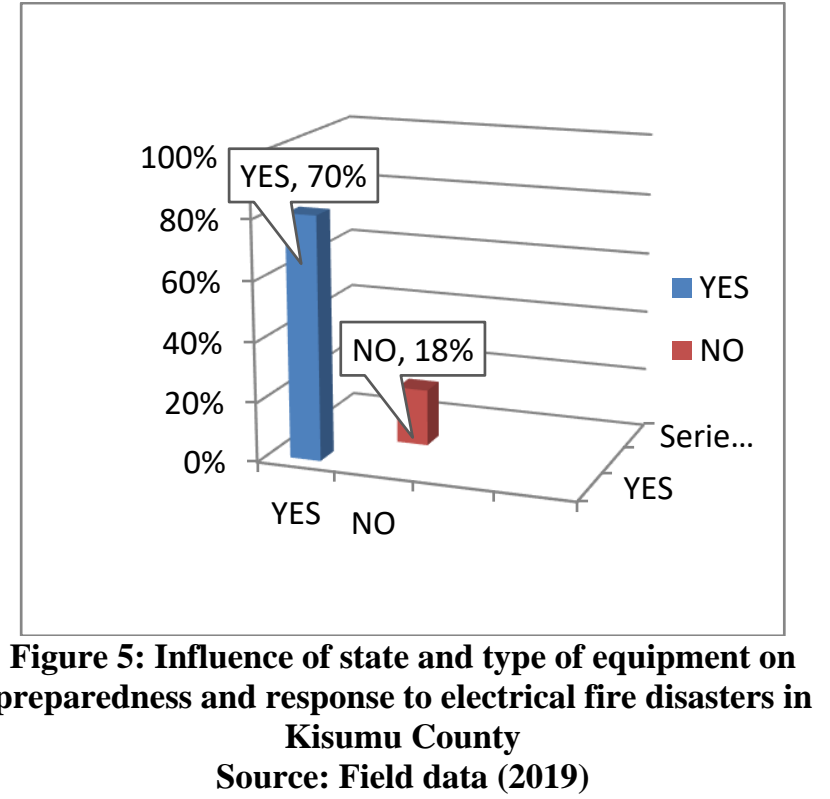

On influence of state and type of equipment on preparedness and response to electric disasters in Kisumu County, out of the response rate of $141(88)$ after excluding the customers connected to electricity grid in Kisumu County, $112(70 \%)$ of the respondents were of the opinion of "YES" while $29(18 \%)$ of the respondents had opinion that state and type of equipment had no influence on preparedness and response to electric disasters in Kisumu County.

In relation to the analysis of figure 5.6, Gravin et al (2017), observes that incorrect manufacturing process and use of not suitable materials may cause loss of characteristics of equipment and failures, which can also be a consequence of: Improper package and transportation and inappropriate storage. Incorrect mounting of equipment and materials in these organizations.

Organizations innovativeness of the system solutions for industrial and public distribution is tailored to individual requirements. Some equipment are effective because there was keen measures taken when making them and this makes them reliably optimize quality of service delivery to towards your goals and also customer satisfactory (Sadikoglu and Olcay, 2014). In this case, power quality solutions could be used in all areas of energy supply: from low-voltage to medium-voltage all the way to the high-voltage level because of the type and the state of equipment used.

According Schwenger et al (2014), a stable energy supply with a standard-compliant voltage is an important economic success factor for all applications and was often a prerequisite for grid connection. System perturbations due to insufficient voltage quality resulted in increased costs and in some instances brought business processes to break down. Power quality solutions at place of business contributed to voltage stabilization, compliance with standards and grid connection requirements and a significant increase in grid efficiency.

It is quite common that many manufacturing units, to reduce production costs, do not use low quality or not suitable materials 
and do not meet applicable standards. Manufacturing errors of materials supplied by others and not controlled by the equipment manufacturer and this was the consequence of lack of a Quality Management System, for instance wrong forging process. Improper package, not suitable for the particular type of equipment, its fragility, and special requirements of transportation, may cause damages, which of them may not be visible with the preliminary inspection that must be done when equipment arrive to site (ASIS, 2009).

Incorrect handling caused several harmful effects on equipment and materials, presenting similar problems to those referred for improper package and a preliminary inspection. These damages were the origin of failures in systems, equipment and materials (Benson et al., 1991).

\subsection{Design Errors of Equipment and Materials Specification}

Sizing equipment, like circuit breakers and switching devices, power transformers, motors and cross section of cables and bus bars, a miscalculation by the designer due to the use of unsuitable calculation tools or a wrong evaluation of the data available caused a permanent overload of those equipment, which leads to overheating and dielectric breakdown, or the destruction of equipment they could not withstand short-circuit thermal and electromechanical stress(Glover and Sarma, 2002).

According to Glover and Sarma (2002), when preparing technical specifications, if there were incomplete definition of the characteristics of equipment, an absence of information about the working conditions of equipment and the lack of definition of applicable standards and wiring regulations, a high risk of using unsuitable materials and manufacturing procedures existed, which led to the risk of failures of equipment and materials.

Okwiri (2012), acknowledges that even in qualified and certified manufacturers with installations that met all the requirements, manufacturing errors and deficiencies happened for instance most common factors for such a situation where: manufacturing equipment and machine tools aged and technologically outdated and not properly maintained, disorganized and incorrect manufacturing processes and procedures, unskilled and not qualified personnel, non-observance of applicable standards, use of low quality or not suitable materials and lack of a Quality Management System and poor or lack of quality control. From the findings, it was indicative that the state and type of equipment highly influenced on the preparedness and response to electric disasters in Kisumu County.

\section{SUMMARY AND CONCLUSIONS}

Most organization have not ensured ISO certification requirements in their management systems. That organizations quality management systems were less effective in relation to electric disasters response.

\section{RECOMMENDATION}

The paper recommends that all organization should implement ISO certification requirements on their management systems. Effect their systems through assistance from other organizations with the same role for effective electric disaster management.

\section{REFERENCES}

[1] Anton, E., Katharine, G., Elvira, M., \& Pedro, (2016). "Independent Power Projects in Sub- Saharan Africa"(PDF). World Bank Group.

[2] ASIS, (2009). Organizational Resilience: Security, Preparedness, and Continuity Management ASTM E1996- 14, ASTM International, West Conshohocken, Pennsylvania. Bass Caused by Hurricanes through Localized Intensity Indices. PES General.

[3] Basir, A.B., Davies, J. \& Rudder, A. (2011). The Elements of Organizational Culture Which Influence the Maintenance of ISO 9001. African Journal of Business Management, 5 (15), 6028 - 6035.

[4] Benson, G., Saraph, V., and Schroeder, R.G. (1991).The effects of organizational context on Society for Quality (2004). www.asq.org, accessed February 15, 2004.

[5] Cavallini, M., Papagni, M.F., \& Preis, B. F.W. (2007). Fire Disasters in the Twentieth Century. Ann Burns Fire Disasters. 20(2): 101-103.

[6] Creech, Bill. (1994). "11: A TQM Path to Tomorrow: New Ways for New Days". The Five Pillars of TQM: How to Make Total Quality Management Work for You. New York: Truman Talley Books. p. 478.ISBN 9780525937258. OCLC 28508067.

[7] Crosby, P. (2012). Milwaukee, Wisconsin: American Society for Quality.

[8] Dennis, A. (2007). "What the Call Center Industry Can Learn from Manufacturing: Part II" (PDF). National Association of Call Centers.

[9] Glover, J.D. \& Sarma, M.S. (2002). Power System Analysis and Design. Brooks/Cole

[10] Gravin. H., Michael, B., \& Edger, S. (2017)."Kenya Energy Situation". Energypedia.info.

[11] Greenwire, N., Michael B; And Nathanial G., (2008). "Droughts Turn Out the Lights in Hydro-Dependent African Nation". The New York Times.

[12] Heavey, C., Ledwith, A. \& Murphy, E. (2014). Introducing a new continuous improvement framework for increased organizational return on investment. The TQM Journal, 26 (6), $594-609$.

[13] Hoyle, E \& David, V. (2005). ISO 9000 Quality Systems Handbook, Fifth Edition. Butterworth-International Limited Publishers.

[14] Juran, C \& Joseph, M. (1995). A History of Managing for Quality:The Evolution, Trends, And Future Directions of Managing for Quality, Milwaukee, Wisconsin.

[15] Juran, J.M. (1992). Juran on Quality by Design: The New Steps for Planning Quality into Goods and Services. Free Press. 22301:2012, International Organization for Standardization, Geneva, Switzerland.

[16] Kothari, R.C. (2004). Research Methodologyand technologies in education.

[17] Krishnamurthy, V. \& Kwasinski, A. (2013). Characterization of Power System. New Kenyan Small and Medium Manufacturing Industries. International Journal of Management.

[18] Marnay C., Venkataramanan, G. Stadler, M. Siddiqui, A. Firestone, R. And Chandran B.(2008). Optimal technology selection and operation of commercial-building microgrids. IEEE Transactions on Power Systems, 2008, 23(3): p. 975-982.

[19] Njenga, J. (2016). Quality management practices and performance of energy sector parastatals in Kenya.

[20] Okwiri, T. (2012). Quality Management Core Practices: A Participatory Action-Based Case.

[21] Otuki, N. (2017). "Kenya moves to third in new geothermal rankings". Business Daily Africa.

[22] Rossi, P.H., Freeman, H.,\& Lipsey,M. 1999. Evaluation: A Systematic Approach 
[23] Sadikoglu, E. \& Olcay, H. (2014). T he Effects of Total Quality Management Practices on Performance and the Reasons of and the Barriers to TQM Practices in Turkey. Advances in Decision Sciences,

$23,1-17$.

[24] Schwenger, D., Straub, T., \& Borzillo, S. (2014) Non-Governmental Organizations: Strategic MISSION.

Sinei, J. C. (2013). The Kenya Power \& Lighting Company Ltd strategies.

[25] Sioshansi, P. (2011). Smart Grid: Integrating Renewable, Distributed \& Efficient Energy.Society. Montreal, Canada.

[26] Su, Q., Li, Z., Zhang, S., Liu, Y. \& Dang, J. (2008). The impacts of quality

[27] Tan, K.C., Kannan, V.J., \& Handfield, R.B. (1998). 'Supply chain management.

[28] Vanya, I. (2015). Power quality management methodology.

\section{AUTHORS}

First Author - Hassero, C., Masinde Muliro University of Science and Technology, Kenya Department of Emergency Management Studies

Second Author - Dr. Nabiswa, F., Masinde Muliro University of Science and Technology, Kenya Department of Emergency Management Studies

Third Author - Rev. Dr. Odhiambo, E .O. S., Masinde Muliro University of Science and Technology, Kenya Department of Emergency Management Studies 